J.C. Currens, R.L. Paylor, E.G. Beck, and B. Davidson - A method to determine cover-collapse frequency in the Western Pennyroyal karst of Kentucky. Journal of Cave and Karst Studies, v. 74, no. 3, p. 292-299. DOI: 10.4311/2011ES0247

\title{
A METHOD TO DETERMINE COVER-COLLAPSE FREQUENCY IN THE WESTERN PENNYROYAL KARST OF KENTUCKY
}

\author{
James C. Currens*, Randall L. Paylor, E. Glynn Beck, and Bart Davidson \\ Kentucky Geological Survey, University of Kentucky, 228 Mining and Mineral Resources Building, Lexington, KY 40506-0107
}

\begin{abstract}
To determine the rate of cover-collapse sinkhole formation in Christian County, Kentucky, we used large scale aerial photographs taken nearly twenty years apart. The negatives were enlarged and printed to 1:3,000 scale and examined for collapses. The photographs constrained the time period within which the collapse could have occurred, and the large scale of the prints provided a means to identify, locate, and field-verify the cover collapses. All features noted on the photographs were checked in the field. Sinkholes seen on the later photographs, but not the earlier ones, were recorded. The rate of formation calculated was 0.2 cover-collapse $\mathrm{km}^{-2} \mathrm{yr}^{-1}$.
\end{abstract}

\section{INTRODUCTION}

Cover collapse is the phenomena of apparently sudden collapse of soil or other unconsolidated cover over karstic bedrock. In Kentucky, cover collapse frequently damages buildings, roads, utility lines, and farm equipment. It has killed livestock, including some thoroughbred horses, and has injured people. The Kentucky Geological Survey estimates a total economic cost of $\$ 20$ million annually in Kentucky from karst-generated geologic hazards (Dinger et al., 2007). The survey records an average of two dozen cover collapses per year and has developed a case history file spanning some thirty years. In this paper, we report a site-specific study of collapse frequency in a small area of the Western Pennyroyal sinkhole plain east of Hopkinsville in Christian County, Kentucky (Fig. 1).

\section{Cover-Collapse Process}

The development of voids in unconsolidated cover overlying karstic bedrock has been studied for decades (Beck, 1991; White and White, 1992). Small voids in soil at depths of a few meters are comparatively stable because of the lateral distribution of the overburden-induced stress by the arched roof of the void. The voids are enlarged by a loss of cohesion and loading of the arch-forming material caused by either a wetting front of soil water from infiltrating precipitation or by rapid draining of an inundated void. The saturated pores in the unconsolidated cover cannot drain as quickly as the conduit-connected void. The wetting and increased pore pressure result in an incremental loss of strength of the regolith arch (Tharp, 1999) and the underside of the arch sloughing into the soil void. Ultimately, the repeated sloughing from wetting and drying of the unconsolidated cover propagates the archedover void to near the land surface (Hyatt and Jacobs, 1996; Waltham et al., 2005). The sudden appearance of a covercollapse sinkhole is initiated when the arch becomes too thin to support its own weight and shears the remaining soil in a nearly circular pattern (Fig. 2). If sufficient volume is not available in the underlying bedrock cavity to store the collapsed soil, the loose material is transported away by groundwater flow through the bedrock conduit. Although the genesis of cover collapse is well understood, precisely predicting the time and place at which a collapse will occur is not yet possible (Hyatt et al., 2001).

\section{Study Area}

The study area is $4.04 \mathrm{~km}^{2}$ in east-central Christian County, Kentucky (Fig. 3). The topography within the study area is karst plain and a single low hill, giving $23.5 \mathrm{~m}$ of local relief, formed by resistance to dissolution of the basal part of the Bethel Sandstone. Land use at the time of the study (2004) was largely pasture and row-cropped fields with scattered farmsteads, a retail agriculture supply store, a cement plant, and a restaurant. The boundaries were defined by the overlapping area of stereo aerial photograph pairs. The study area was selected without any prior knowledge of existing cover collapses in the area.

The exposed Mississippian section, in ascending order, is Ste. Genevieve Limestone, Renault Limestone, and Bethel Sandstone (Klemic, 1967). The bedrock at the base of the stratigraphic column is predominantly oobiosparites and micritic limestones, medium- to thick-bedded, and is greater than 95 percent calcium carbonate. Interbedded thin shale and argillaceous carbonates are a minor interruption to the otherwise very pure carbonate section. The residual $10 \mathrm{~m}$ of Bethel is a calcite-cemented, argillaceous quartzarenite that weathers into a friable, porous, sandy residuum that readily slumps into underlying sinkholes (Klemic, 1967). The Lost River Chert is exposed near the base of the Ste. Genevieve in local quarries, but is below the depth of karst development in the study area. The exposed Ste. Genevieve Limestone is

*Corresponding Author: currens@uky.edu 


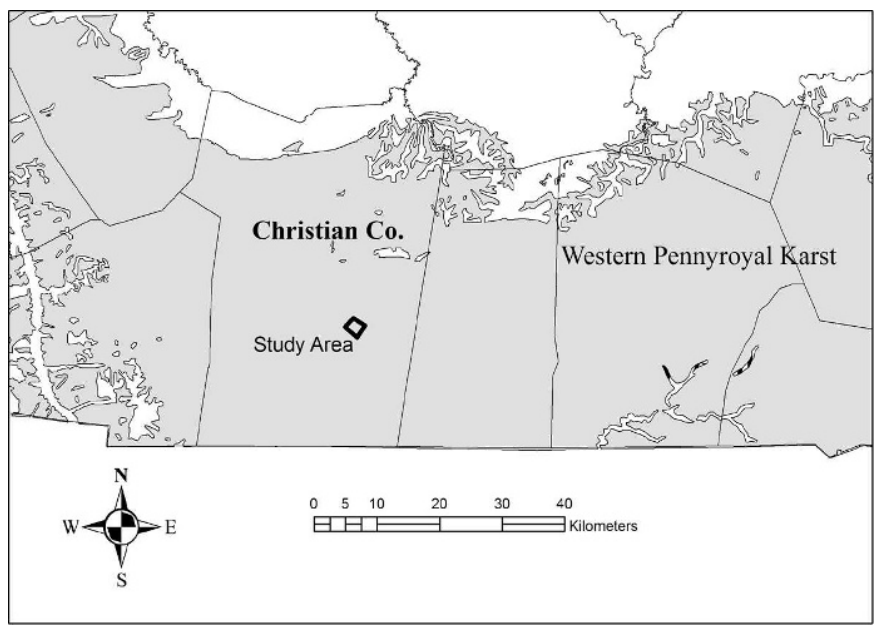

Figure 1. The black polygon is the study area in Christian County, east of Hopkinsville, Western Pennyroyal region in Kentucky. The gray shaded area is underlain by karstic carbonates.

over $52 \mathrm{~m}$ thick, while the Renault Limestone is some 15 to $29 \mathrm{~m}$ thick. The regional gentle dip of $3 \mathrm{~m} \mathrm{~km}^{-1}$ to the north is the only structure in the otherwise flat-lying bedrock at the study site.

The cover collapses inventoried were mostly in the outcrop area of the Renault. Because of the purity and thickness of the carbonates, the presence of topographically mapped dolines, and the moderate total relief of $60 \mathrm{~m}$ within the study area, we expected the rate of occurrence of cover collapse to be comparatively high. The conditions in the study area are nearly ideal for cover-collapse development.

\section{Methods}

We used a simple and inexpensive method to locate sinkholes and constrain the time of cover collapse. Because we did not have access to a magnifying stereoscope, the Kentucky Geological Survey purchased prints of blackand-white, low-altitude, large-scale, visible-light, aerial photography at an imaged scale of 1:12,000 $(1 \mathrm{~cm}=$ $120 \mathrm{~m}$; $1 \mathrm{in} .=1,000 \mathrm{ft}$ ) from the Tennessee Valley Authority. The photographs were taken March 9, 1971, and January 31, 1991. Although we also obtained stereo sets of contact prints, the most useful images were enlargements of the central image from the sets. The enlargements were printed at a scale of 1:3,000 $(1 \mathrm{~cm}=$ $30 \mathrm{~m}$; $1 \mathrm{in}=250 \mathrm{ft}$ ), four times the scale of the negative. Using 2-power magnifying glasses, we visually scanned the enlargements systematically for features appearing to be sinkholes. The emulsion grains on the print were sufficiently small in comparison with the typical cover-collapse that shadows cast on the interior of a collapse less than a meter in diameter could be discerned from those cast by small cedar trees, for example. Further, labeling devices

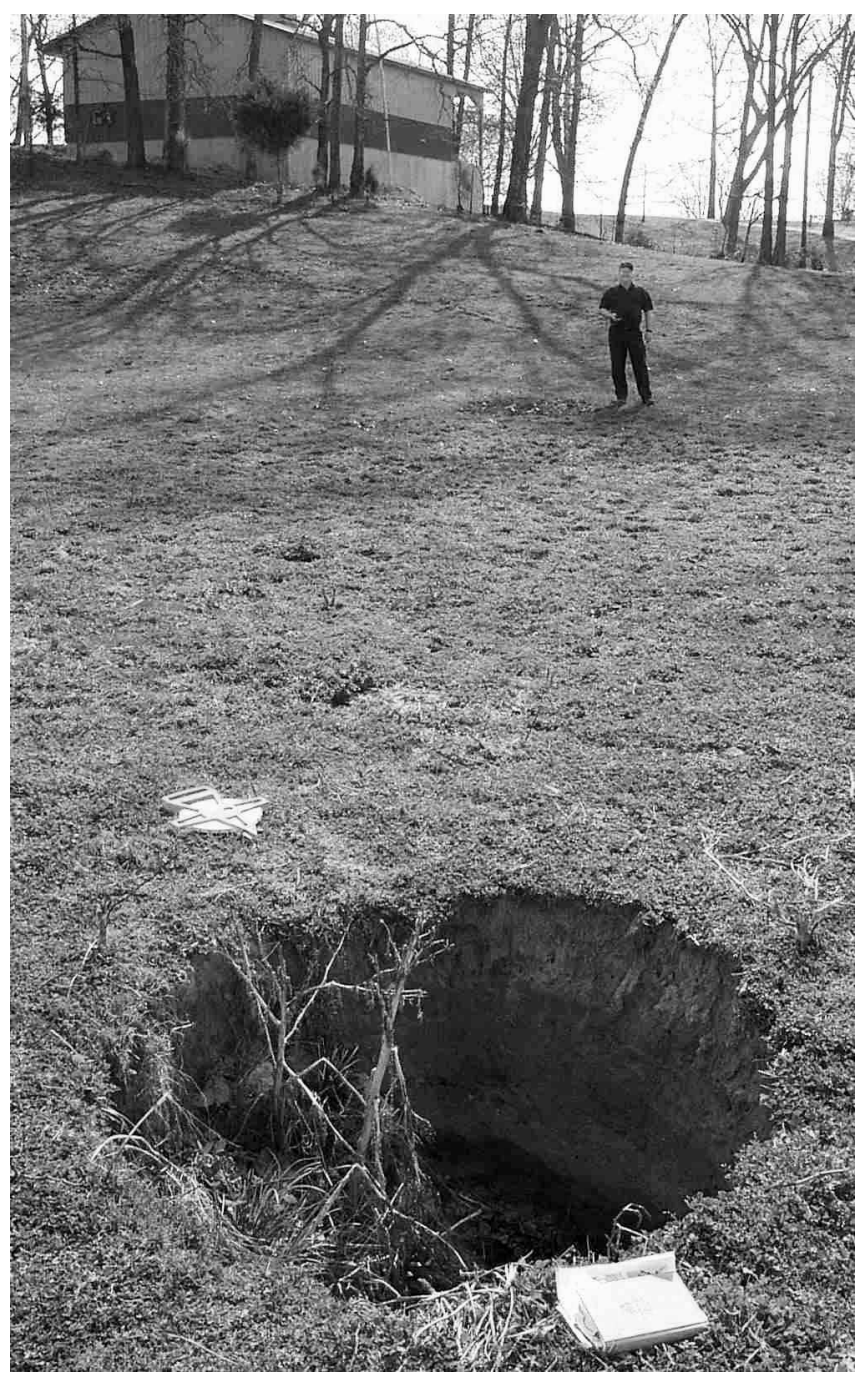

Figure 2. A classic example of a cover collapse in the study area.

could be attached to the enlargement print to preserve the interpretive data.

We also searched for cover-collapse features on the stereo-pair contact prints and the digital images made at the KGS from scans of the enlargements. Most of the features identified on the 1:3,000-scale enlargements could not be relocated with confidence on the 1:12,000-scale contact prints. Scanned enlargements were saved as 16-bit gray-scale TIFF files at 1,200 dpi, giving a pixel size of roughly $0.5 \mathrm{~m}$ at ground level. The file size was large $(428,853 \mathrm{~kb})$ and prevented viewing the scan with image viewers on most of the available computers. We did view the images with GIS software, but could not relocate any cover-collapse locations on the digital images due to pixilation.

Fifty potential cover-collapse sites were selected for field inspection from the enlarged prints (Table 1). KGS staff field-checked all of the sites and determined if they were, in fact, cover collapses. Those sites that had developed within

Journal of Cave and Karst Studies, December 2012 •293 


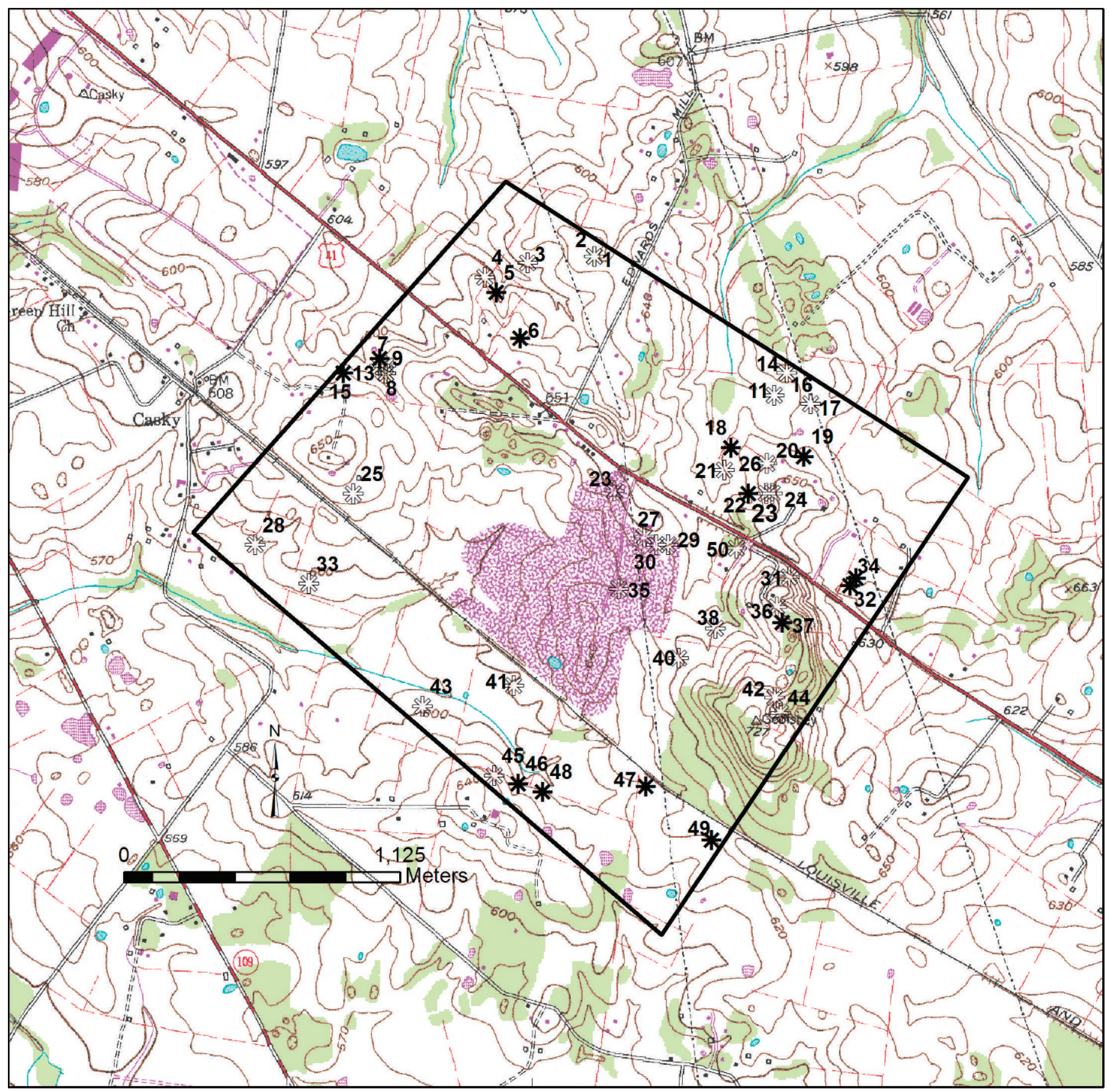

Figure 3. The cover-collapse inventory area in the Hopkinsville 7.5-minute quadrangle is inside the black line. The disrupted textured area enclosed by a gray line is the property of a limestone quarry, which was excluded from the inventory. Solid asterisks are cover-collapse sinkholes identified on the 1991 aerial photograph and verified in the field. Hollow asterisks are other features from the same images determined not to be cover-collapse.

the twenty-year period bracketed by the photographs were identified. We also found a small number of cover collapses that did not appear until after the 1991 photography. These were too recent to include in the calculation of the rate, but were documented for future reference. Some features that were visible on the earlier photographs, but not on the later ones, were also noted. We also received a limited number of reports that a collapse had occurred and had been filled and graded during the period between the aerial photography. Such cover collapses were included in the rate calculation only if we found field evidence that the report was correct. Field evidence for a filled sinkhole included a circular variation in texture and color of vegetation, buried trash exposed at the surface, subsidence due to soil compaction, or 


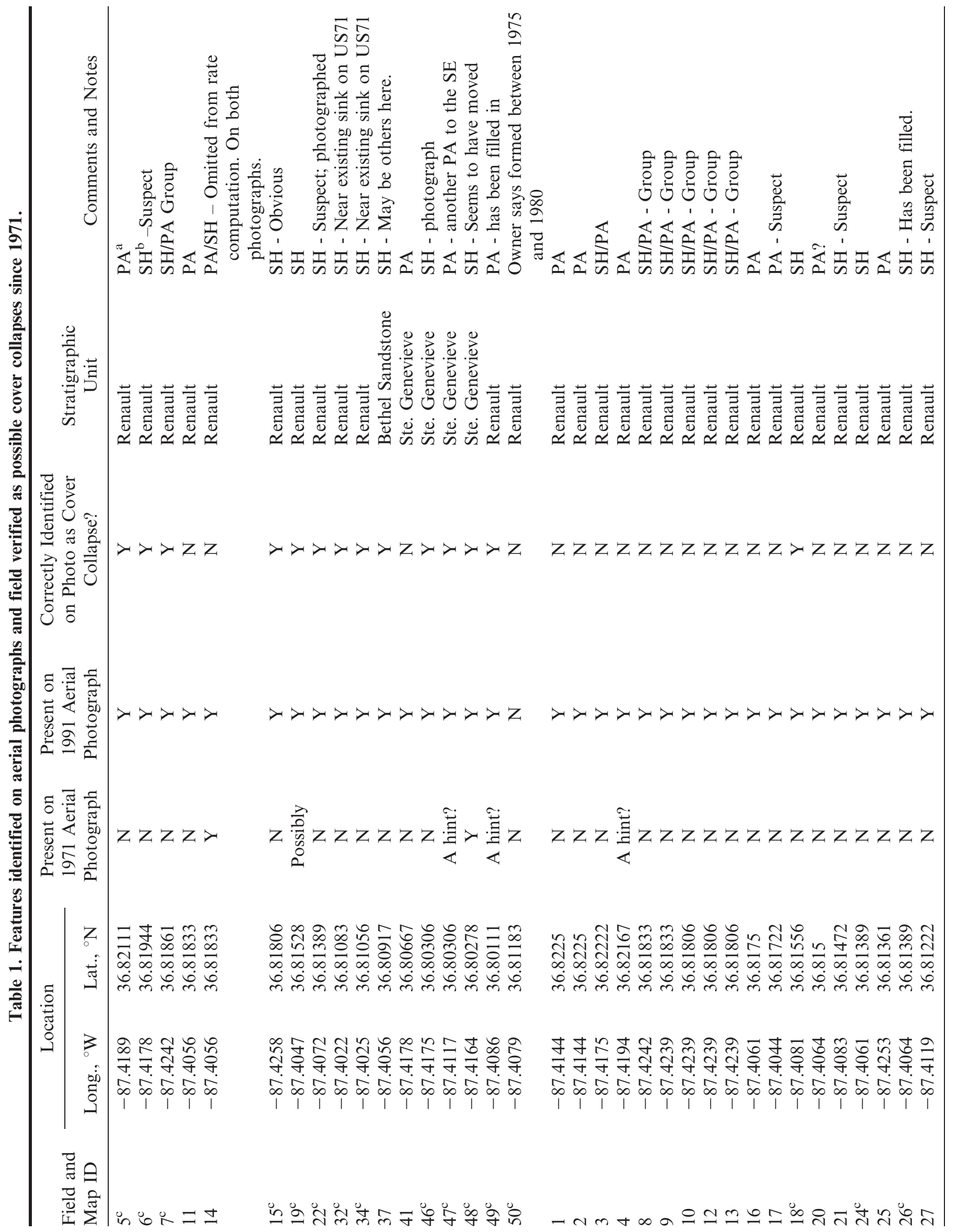




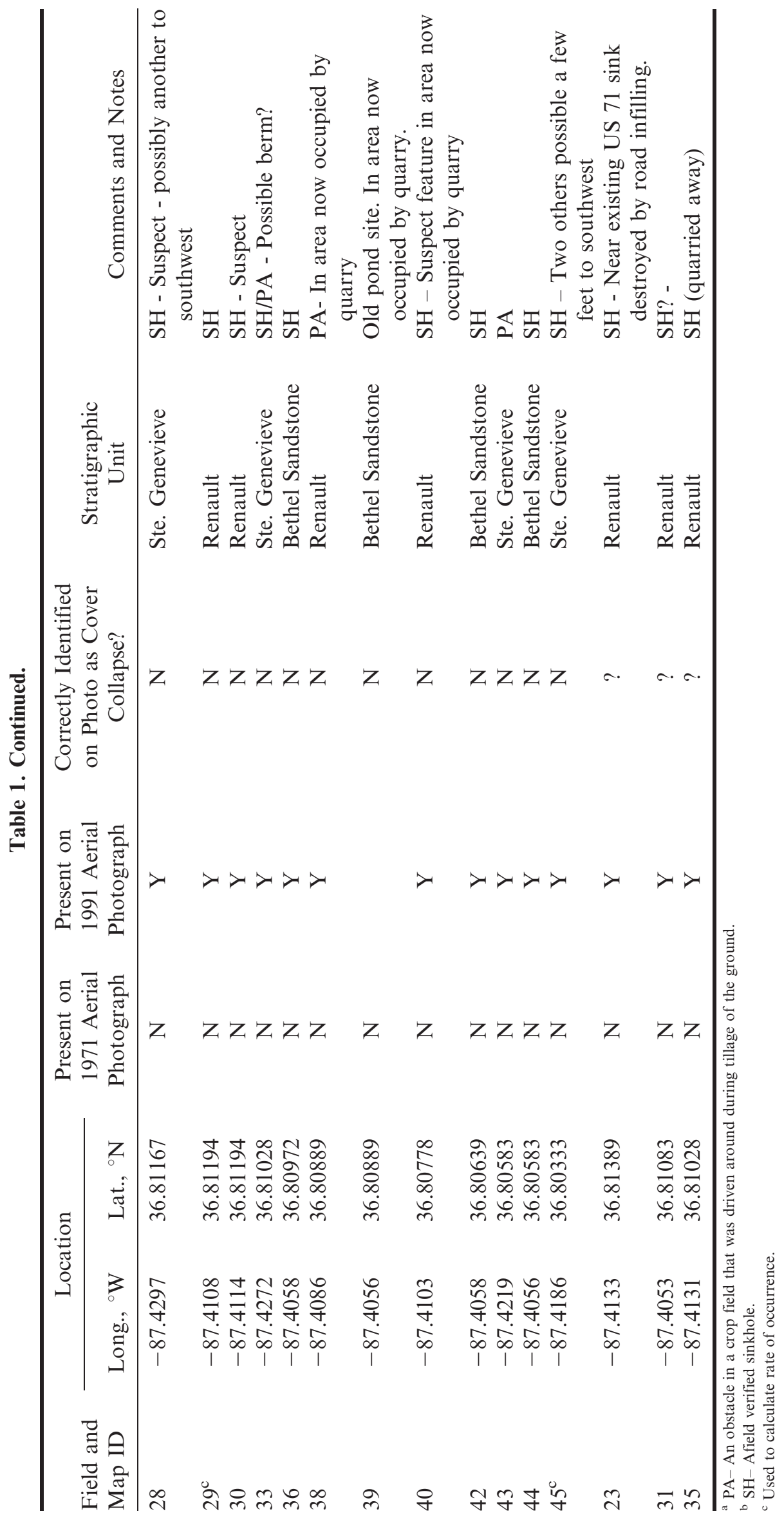




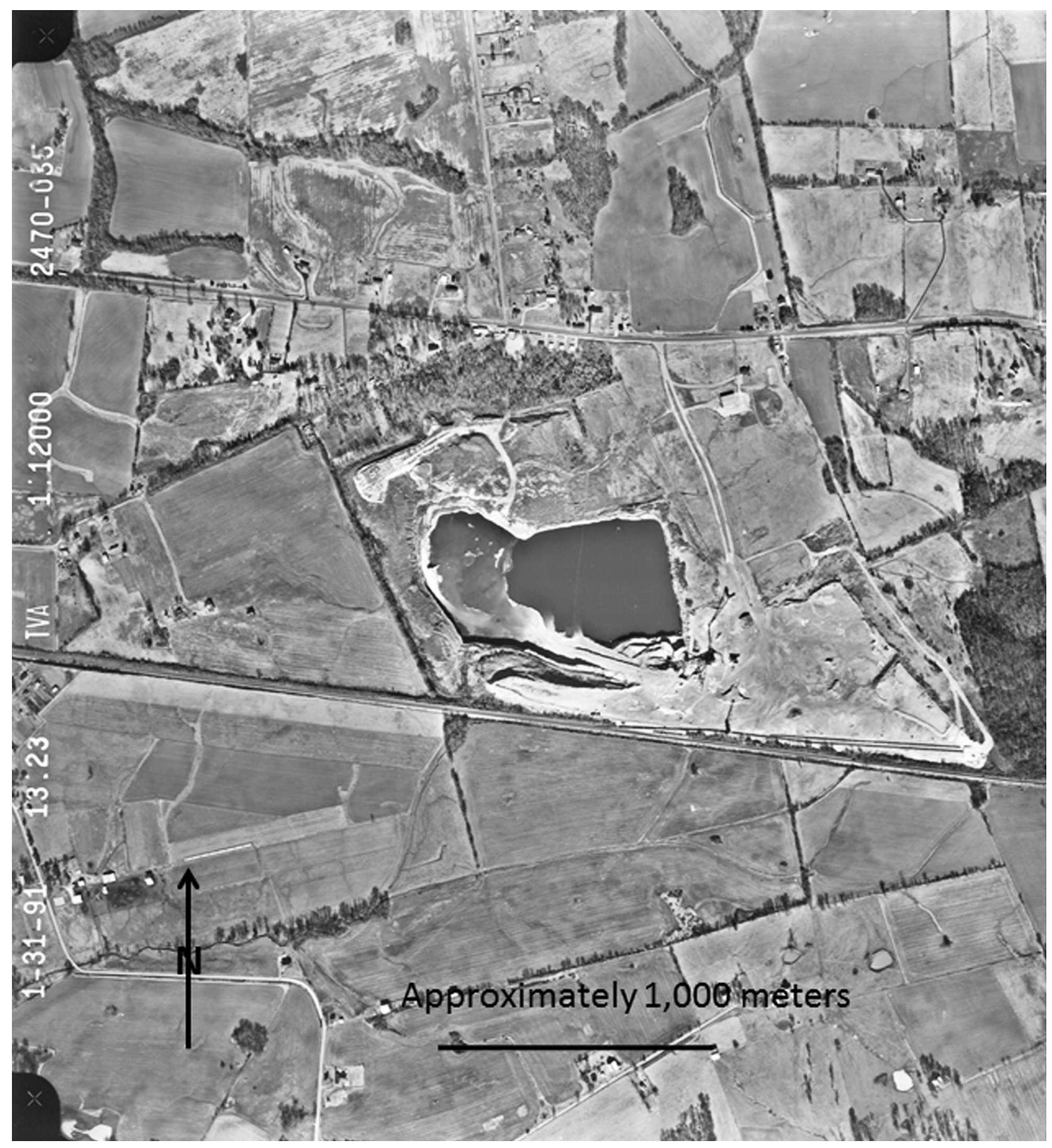

Figure 4. The 1991 aerial photograph of the study area in the Hopkinsville East 7.5-minute quadrangle, Christian County, $\mathrm{Ky}$. The dark area in the center is the now-flooded limestone quarry that was excluded from the analysis. North is at the top the photograph. The scale of the negative is $1: 12,000$.

a local change in soil color if the soil was bare. After comparing recent sinkholes to sinkholes that are clearly old, we think that insufficient time has passed in the 35 years between the earlier photography and our study for any recent cover collapses to have been naturally obscured by slumping and erosion. Finally, our method does not work in wooded areas, although woodlands can still be field-checked, which we did. No cover collapse was found in the small wooded area.

\section{Limitations on Data Analysis}

The primary goal of this study was the demonstration of the technique, and we anticipated several limitations on 
the accuracy of the cover-collapse rate. The aerial coverage obtained from TVA has one of the largest scales available, and it is only available in Kentucky for the Tennessee River Valley. The limited area of photography restricted the selection of study areas. Although the area was well suited for cover collapse, we had some concern that none would be identifiable on the images or that no collapses had actually occurred in the study area. This proved unfounded. Third, the size of the study area was limited by the budget, which resulted in it being too small for a statistically significant sampling (Beck, 1991) that would be representative of the larger region. Ideally, an area of 10 or more square miles should be used, or several smaller sampling sites scattered over the region.

Large-scale photographic prints are not commonly used because of the increased cost of processing the prints necessary to cover the same area on the ground when compared to contact prints. It may become increasingly difficult to obtain contact prints and enlargements of traditional analog photography because of the closure of processing facilities. As of February 2010, the Tennessee Valley Authority still offered the enlargement service that KGS utilized (https://maps.tva.com/Scripts/MetaWeb/map_ aerial.asp).

More problematic was a misunderstanding between the Kentucky Geological Survey and the Tennessee Valley Authority about the area to be covered. The KGS intended the quarry (the large dark area in the center of Fig. 4) to be a reference landmark outside of the photograph frame, not the object of the exercise. We did not realize the photographs encompassed the stone quarry until we received them. It was not possible to replace the prints. The staff of the stone quarry was contacted, and they stated that the quarry opened shortly after 1971 and operated less than ten years. They were not aware of any history of cover-collapse sinkholes induced by dewatering the quarry. The quarry occupies $0.88 \mathrm{~km}^{2}$ or 18 percent of the study area. Only one probable cover collapse was found within the quarry area on the 1971 image, and it could not be verified in the field because its location had been mined by 1991 . We could not find any obvious pattern that suggested induced sinkhole clustering near the quarry, either in the field or on the photographs. We think the effect of the quarry and the study was negligible beyond the obvious loss of study area.

Two of the features of the area, quarry dewatering and highly favorable geology, potentially inflate the population of cover-collapse features and one of the others, uncounted sinkholes that occurred and then were filled between photographs, possibly deflates the count. Further, if cover collapses occurred during the period between the two photos that we did not find, these would lead us to underestimate the rate of formation. Because of the pure, thick limestone and $60 \mathrm{~m}$ of relief within the study area, we think our rate of sinkhole formation should be considered a maximum for application to other areas.

\section{RESULTS}

We identified fifty cover-collapse like features that occurred between 1971 and 1991 from the aerial photograph and reports from local residents. The photographic enlargements made possible the identification of the features and their location in the field. The detail of the photographic enlargement was an important factor in the success of the technique.

Also, we physically examined an estimated 90 percent of the study area. Of the fifty possible sites identified on the photographs, thirteen could not be found in the field and there was no evidence of collapse in the vicinity of the feature seen on the photograph. Of the remaining thirtyseven sites, sixteen (43 percent) were correctly identified on the photographs as to origin (whether cover-collapse or not) when located in the field. Fifteen of the cover-collapse sinkholes were accurately identified on the photographs and verified in the field, the remaining collapses were thought some other feature until field checked (Table 1). One cover collapse identified on the 1991 enlargement was also on the 1971 image and was not counted (Table 1). Ultimately, a total of eighteen sites were determined to be cover collapses that occurred within the time frame of the two images.

The primary benefit of the photographic enlargements was they directed us where to focus our field work. The total cover collapses correctly identified from the photographs (36 percent of the total features and 43 percent of the features that could be found in the field) is a useful success rate, but could be expected to improve with experience.

Calculation of the rate of formation of the covercollapse is subject to the limitations cited above. We excluded the area of the quarry as defined by the property line (Fig. 3) from the rate calculation. The rate of covercollapse events for the study area is $0.2 \mathrm{~km}^{-2} \mathrm{yr}^{-1}$

Table 2. Results of inventory and field-verified cover-collapse events between aerial photographs by TVA in 1971 and 1991 (19.9 years).

\begin{tabular}{lcccc}
\hline $\begin{array}{l}\text { Area if Quarry } \\
\text { Included/Excluded }\end{array}$ & $\begin{array}{c}\text { Count, Cover-Collapse } \\
\text { Sites }\end{array}$ & $\begin{array}{c}\text { Cover Collapse per } \\
\text { Inventory Area, } \mathrm{km}^{2}\end{array}$ & $\begin{array}{c}\text { Cover Collapse/Unit } \\
\text { Area/Year, } \mathrm{km}^{-2} \mathrm{yr}^{-1}\end{array}$ \\
\hline Included & 18 & 4.92 & 3.7 & 0.18 \\
Excluded & 18 & 4.04 & 4.5 & 0.22 \\
\hline
\end{tabular}


(0.6 $\mathrm{mi}^{-2} \mathrm{yr}^{-1}$; Table 2), which is consistent with some previous studies. Hyatt et al. (1996) reported more than 312 cover collapses in the vicinity of Albany, Georgia, that developed within a $25 \mathrm{~km}^{2}$ study area within a week following a tropical storm in July 1994. The density of the features ranged from $0.09 \mathrm{~km}^{-2}$ to $5.3 \mathrm{~km}^{-2}\left(0.21 \mathrm{mi}^{-2}\right.$ to $13.7 \mathrm{mi}^{-2}$ ). A follow-up study by Hyatt et al. (1999) is perhaps the most complete descriptive study of covercollapse sinkholes in the United States to date. We used their data to calculate the occurrence of cover-collapse at 12.5 events per square kilometer over the one week observation period. The minimum annual rate based on the 1994 data would be $0.2 \mathrm{~km}^{-2} \mathrm{yr}^{-1}$. Beck (1991) reported $0.11 \mathrm{~km}^{-2} \mathrm{yr}^{-1}\left(0.29 \mathrm{mi}^{-2} \mathrm{yr}^{-1}\right)$ in Florida, and Ketelle et al. (1988) reported a range of 0.04 to $0.64 \mathrm{~km}^{-2} \mathrm{yr}^{-1}$ (0.1 to $1.69 \mathrm{mi}^{-2} \mathrm{yr}^{-1}$ ) in eastern Tennessee. Wilson et al. (1987) reported $0.01 \mathrm{~km}^{-2} \mathrm{yr}^{-1}\left(0.04 \mathrm{mi}^{-2} \mathrm{yr}^{-1}\right)$, also in Florida.

\section{Conclusions}

The use of enlargements of conventional aerial photography to both locate and constrain the date of formation of cover-collapse sinkholes proved practical, inexpensive, and reasonably robust for the sinkhole plain of the Western Kentucky Pennyroyal. Although ground inspection is still needed, field work, regardless of how thorough, can only grossly estimate when an unobserved collapse occurred. The photography-based field inventory was possible because the land use of the study area was dominated by pasture and crop fields. Except for any undiscovered cover-collapse sinkholes that occurred and were filled in the interim between photographs, the method can be categorized as exhaustive.

In the study area, cover collapse occurs at $0.2 \mathrm{~km}^{-2} \mathrm{yr}^{-1}$ $\left(0.58 \mathrm{mi}^{-2} \mathrm{yr}^{-1}\right)$, consistent with most previous studies. Because of the favorable geology of thick, pure carbonates, the rate calculated here should be considered a maximum if applied to other karst areas in Kentucky.

\section{REFERENCES}

Beck, B.F., 1991, On calculating the risk of sinkhole collapse, in Kasting, E.H., and Kasting, K.M., eds., Appalachian Karst, Proceedings of the Appalachian Karst Symposium, Radford, Virgina, March 23-26, 1991: National Speleological Society, Huntsville, p. 231-236.

Dinger, J.S., Zourarakis, D.P., and Currens, J.C., 2007, Spectral enhancement and automated extraction of potential sinkhole features from NAIP imagery - initial investigations: Journal of Environmental Informatics, v. 10, no. 1, p. 22-29. doi:10.3808/ jei.200700096.

Hyatt, J.A., and Jacobs, P.M., 1996, Distribution and morphology of sinkholes triggered by flooding following Tropical Storm Alberto at Albany, Georgia, USA: Geomorphology, v. 17, p. 305-316. doi:10.1016/0169-555X(96)00014-1.

Hyatt, J.A., Wilkes, H.P., and Jacobs, P.M., 1999, Spatial relationships between new and old sinkholes in covered karst, Albany, Georgia, USA, in Beck, B.F., Pettit, A.J., and Herring, J.G., eds., Hydrogeology and Engineering Geology of Sinkholes and Karst: Rotterdam, Balkema, p. 37-44.

Hyatt, J.A., Wilson, R., Givens, J.S., and Jacobs, P.M., 2001, Topographic, geologic, and hydrogeologic controls on dimensions and locations of sinkholes in thick covered karst, Lowndes County, Georgia, in Beck, B.F., and Herring, J.G., eds., Proceedings of Geotechnical and Environmental Applications of Karst Geology and Hydrology, Rotterdam, Balkema, p. 37-45.

Ketelle, R.H., Newton, J.G., and Tanner, J.M., 1988, Karst subsidence in East Tennessee, in Proceedings $2^{\text {nd }}$ Conference on Environmental Problems in Karst Terranes and Their Solutions: Dublin, Ohio, National Water Well Association, p. 51-65.

Klemic, H., 1967, Geologic map of the Hopkinsville quadrangle, Christian County, Kentucky: U.S. Geological Survey, Geologic Quadrangle Map GQ-651, scale 1:24,000.

Tharp, T.M., 1999, Mechanics of upward propagation of cover-collapse sinkholes: Engineering Geology, v. 52, p. 23-33. doi.org/10.1016/ S0013-7952(98)00051-9.

Waltham, T., Bell, F., and Culshaw, M., 2005, Sinkholes and Subsidence: Karst and Cavernous Rocks in Engineering and Construction: New York, Springer-Praxis Books in Geophysical Sciences, $382 \mathrm{p}$.

White, W.B., and White, E.L., 1992, Sinkholes and sinkhole collapses in Majundar, S.K., Forbes, G.S., Miller, E.W., and Schmalz, R.F., eds., Natural and Technological Disasters: Causes, Effects and Preventative Measures, Pennsylvania Academy of Science, p. 280-293.

Wilson, W.L., McDonald, K.M., Barfus, B.L., and Beck, B.F., 1987. Hydrogeologic Factors Associated with Recent Sinkhole Development in the Orlando Area, Florida; Florida Sinkhole Research Institute, University of Central Florida, Report No. 87-88-4, $109 \mathrm{p}$. 